\title{
The effect of fashion leadership and sustainable clothing attributes on purchase intention: case of a school-sponsored store
}

\begin{abstract}
In an attempt to meet the increasing demand for sustainable fashion products, apparel companies are trying to integrate sustainable practices such as organic fashion, zero-waste design, and local production, but are continually challenged to develop sustainable clothing that is perceived as fashionable. This study examined the effect of fashion leadership and clothing attributes on college student's purchase intention of ten sustainable products that were developed for a school-sponsored store. Findings suggest that general appearance and style/fashion were the most significant influencers of purchase intention, although sustainable products can be attractive to young consumers regardless of their fashion leadership level.
\end{abstract}

Keywords: fashion leadership, sustainability, clothing attributes, purchase intention
Volume 2 Issue I - 2017

\author{
Kim HY Hahn,' Qiong Sarah Tao² Catherine \\ Amoroso Leslie' \\ 'Kent State University, USA \\ ${ }^{2}$ North Carolina State University, USA
}

Correspondence: Kim HY Hahn, The Fashion School, Kent State University, PO Box 5190/ 515 Hilltop Drive, Kent, $\mathrm{OH}$ 44242-000 I USA, Tel I330672 I453, Fax I3306723772, Email khahn6@kent.edu

Received: May 12, 2017 | Published: June 14, 2017

\section{Introduction}

The global fashion industry encompasses a variety of stakeholders "who collaborate to design, manufacture, and sell clothing, shoes, and accessories". ${ }^{1}$ It is among the largest in the world, valued at approximately 1.7 trillion U.S. dollars and employing more than 75 million individuals. ${ }^{2}$ In recent years, this industry has also been noted for its negative environmental impact. As awareness becomes more widespread, a growing number of consumers are concerned over conventional fashion production practices, supporting an increasing demand for sustainable products. ${ }^{3}$ Every stakeholder in the supply chain plays a role in implementing sustainability: consumers, designers, retailers, and other industry insiders can all have a significant influence on environmental and social concerns. ${ }^{4}$ As fashion companies attempt to incorporate more sustainably-produced product offerings, they have been met with a challenge. The bulk of consumers are reluctant to purchase these items, and while price is always a consideration, part of the blame can be placed on a lack of fashion ability. ${ }^{5}$ The fashion industry is seeking to position sustainable fashion as trendy, so it will appeal to a wider market. ${ }^{6}$

This study centered on the small-scale design and local production of fashion products by students for a school-sponsored retail store. A key to success in fashion product development is the ability to interpret trends that will appeal to a target market. This appeal is largely dependent on adoption by fashion leaders.

Fashion leadership is used to describe consumers with a greater than average interest in fashion trends. Individuals who exhibit a high level of fashion leadership purchase new fashionable items relatively earlier than the rest of the market and influence later buyers to purchase new in-style items. ${ }^{7,8}$ Research has found that fashion leadership can be a strong predictor of consumer acceptance and purchasing behavior. The phenomenon of fashion leadership has been utilized extensively to understand consumers with differing levels of fashion leadership and its relationship to involvement in fashion products, purchase decisions, consumption, and advertising. ${ }^{9,10}$
How consumers perceive a product's attributes and how those perceptions are affected by fashion leadership are critical issues in studying fashion consumer behavior and product development. ${ }^{11}$ Research has investigated the influence of clothing attributes on consumers' purchase intentions and found that consumers are significantly influenced by different attributes when determining overall acceptance of fashion products. ${ }^{12-16}$ In the case of fashion items, an additional consideration is fashion leadership which influences product evaluation and purchasing of products. ${ }^{7,17-21}$

Although previous studies have examined relationships among fashion leadership, clothing attributes, and purchase intention to study fashion product consumer behavior, no studies have applied these constructs to investigate specific sustainable fashion products developed for a particular store and evaluated by potential consumers. Therefore, the purpose of this study was to examine the effect of fashion leadership and clothing attributes on purchase intention of ten sustainable products that were developed for a school-sponsored store.

\section{Literature review}

\section{Conventional fashion production practices and envi- ronmental impact}

The fashion industry's environmental impact is significant, especially in production processes; each stage of garment making has the potential for numerous negative consequences on the environment. ${ }^{22,23}$ Furthermore, as fashion production locations are scattered across world to be price-competitive, delivering products from low-labor-cost countries to consumers in other parts of the world furthers the destructive impacts..$^{24,25}$

\section{Sustainable production}

With emerging concerns about the fashion industry's impact on the environment, a growing number of apparel companies are trying to integrate sustainable practice and smart sourcing into their 
business models. ${ }^{26-28}$ Leading apparel brands such as Patagonia, Stella McCartney, Loom state, Eileen Fisher, and NAU are actively implementing sustainable practices with positive results. Three evolving practices in the production of sustainable fashion are organic materials, zero-waste design, and local production.

\section{Organic fashion}

Some companies have begun reducing toxic chemicals used in growing and manufacturing fibers. The term "organic" is used to describe products that have adopted a certain level of sustainability. "Organic fashion refers to clothing and accessories that have been made with a minimum use of chemicals and limited impact on the environment". ${ }^{29}$ An increasing number of apparel companies create quality garments and build successful brands while aligning with sustainable practices such as using recycled content, organic, and local sustainable material. ${ }^{30,31}$

Zero-waste design: In traditional clothing manufacturing, significant waste is created in the "fallout" or fabric remaining when pieces are cut. "The way in which the fashion industry uses fabric to create garments is arguably wasteful and inefficient". ${ }^{32}$ Zero-waste challenges the designer to develop garments that fit together like a puzzle, conserving the 15 percent of fabric discarded in making the typical garment. ${ }^{33}$ These efforts coincide with a "fundamental change in our culture when it comes to recycling and sustainability". ${ }^{34}$ Designers Tara St. James, Yeohlee Teng, and Mark Liu are known for their high-quality fashions created through zero-waste processes. ${ }^{35}$

Local production: To address the environmental impact of transportation, fashion companies are taking a serious look at logistics and distribution Caniato et al. ${ }^{25}$ Conventional manufacturing uses "raw materials that are often sourced from distant locations and subcontracts production activities to different companies scattered across the world" Caniato et al. ${ }^{25}$ A newly developed sustainable model in New York City demonstrates the benefits of local apparel manufacturing by reducing transportation costs. ${ }^{26,27}$ "Where fashion is concerned, the time is now for a sustainable, 'Made in America' resurgence". ${ }^{26}$ In addition to reducing environmental impacts, "Domestic and local manufacturing gives designers and management more control over the products they bring to market. It allows them to tweak their designs and products without confronting the delays and inefficiencies involved in ordering from overseas manufacturers". ${ }^{36}$

\section{Consumer demand for sustainable products}

The fashion industry's negative environmental impact has gained attention in recent years. Consumers are realizing their purchasing behavior can exasperate problems and are demanding sustainable products. ${ }^{23}$ According to the Organic Trade Association, ${ }^{37}$ retail sales of products using organic cotton reached a $\$ 5.16$ billion in 2010; a 20 percent increase from the 2009. Furthermore, The Nielsen Global Survey on Corporate Social Responsibility ${ }^{38}$ showed that 55\% of today's global consumers are willing to pay more for socially responsible products. However, consumer behavior varies with values and attitudes, store preference, shopping behavior, demographics, and other lifestyle characteristics. ${ }^{39}$

The true test of success in the fashion industry is seen at the retail level. The product concept must be unique or fulfill a consumer need and, at the same time, be marketable. ${ }^{40}$ Barriers have arisen between clothing that is produced sustainability and consumer's willingness to purchase. The demand for sustainable fashion items "is not at a viable level given the rate at which they are selling" D Souza et al. ${ }^{6}$

\section{Fashion leadership}

Fashion consumer groups can be categorized into fashion leaders and fashion followers.$^{41}$ High fashion leaders are the first to buy and wear new fashions, persuading others to follow. ${ }^{41}$ Research shows that fashion leadership purchasers differ in many consumer behaviors, including their evaluation and purchasing of products. , $17-21,42^{2}$

Fashion leadership is particularly important in developing sustainable clothing that is perceived as fashionable. ${ }^{5}$ found that fashion leaders may not show intention to purchase the sustainable clothing currently available. It "might not be innovatively fashionable yet or green is not yet the new black" (p. 189).

\section{Clothing attributes}

Consumers evaluate clothing attributes such as fit, durability, ease of care, price, comfort, quality, color, attractiveness, fashion ability, brand name, appropriateness of occasion, and style. ${ }^{42-44}$ Fashion and style, price, quality, selection, and company reputation were found to be especially important to certain consumers. ${ }^{45}$ High fashion leaders differed from low fashion leaders in their preferences for the clothing attributes of imported apparel Beaudoin et al. ${ }^{42}$ Based on previous research about different levels of fashion leadership and clothing attributes, we hypothesize following:

A. H1: The high and low fashion leadership groups will have different scores for clothing attributes for each product.

\section{Purchase intention}

The most important criterion for apparel assessment were style, color/pattern, fabric, and appearance, with styling the most often-used category Eckman et al. ${ }^{39}$ Style and fashion were found to be the most important apparel attributes for teenagers and women. ${ }^{43,46}$ Based on previous studies on clothing attributes and purchase intention, we hypothesize following:

A. H2: Clothing attributes such as style, color, and general appearance will have a positive influence on purchase intention.

\section{Fashion leadership and purchase intention of sustaina- ble fashion products}

Fashion leaders have a unique self-concept and seek new fashion items to express their view of themselves. ${ }^{47-52}$ Fashion leaders placed greater importance on excitement and fun/enjoyment than fashion followers. ${ }^{7,53}$

Thus, consumers with high fashion leadership have different sets of values and psychological characteristics from average consumers. Fashion leaders can be advisers and role models to fashion followers. ${ }^{54}$ Based on previous studies on fashion leadership, clothing attributes, and purchase intention, we hypothesize the following:

A. H3: Participants with high fashion leadership scores will have higher clothing attribute scores and higher purchase intentions for certain products.

In the quest to address negative environmental impacts of fashion clothing production, there is a trend towards implementing sustainable practices including organic fabrics, zero-waste design, and local production. Consumer demand for sustainable fashion is growing but has yet to reach a viable level. Research has shown 
that consumers with high fashion leadership have the potential to influence the buying behavior of others. Consumers use clothing attributes to evaluate what they will purchase. Higher ratings on attributes by fashion leaders can provide insights into those products that may have a greater chance of consumer acceptance. Furthermore, positive purchase intention by fashion leaders can inform industry professionals as to which sustainable products may be more marketable than others. This study explored these concepts with ten sustainable products that were developed for a school-sponsored store.

\section{Materials and methods}

\section{Methodology}

In this study, students created sustainable fashion apparel products to be sold in the school-sponsored store (the FSSTORE). Ten women's garments were produced including a White Crop Top, Laser Cut Top, Sweatshirt, "FS" (Fashion School) Print Skirt, Wrap Skirt, Drawstring Skirt, Maxi Dress, Red Jacket, Vest, and Blue Hooded Jacket in Table 1 .

Table I Garment description

\begin{tabular}{|c|c|c|c|}
\hline Product & Description & Product & Description \\
\hline \multirow[t]{4}{*}{ Wrap Skirt } & $\begin{array}{l}100 \% \text { cotton up cycled fabric. Floral wrap } \\
\text { skirt with tic at waistband. }\end{array}$ & Reversible Vest & $98 \%$ cotton $2 \%$ spandex stretch \\
\hline & & & denim with digitally printed $100 \%$ \\
\hline & & & Cotton twill floral lining. \\
\hline & & & Zero waste pattern development. \\
\hline \multirow[t]{3}{*}{ Cut Top } & $100 \%$ polyester jersey. & Red Jacket & $98 \%$ cotton $2 \%$ spandex stretch \\
\hline & Laser cut crop top in navy. & & denim jacket using minimum \\
\hline & & & Waste pattern development. \\
\hline \multirow[t]{4}{*}{ Blue Hooded Jacket } & I00\% cotton twill with & White Crop Top & $100 \%$ cotton sleeveless crop top \\
\hline & drawstring waist and lined & & with self-binding using up cycled \\
\hline & hood using zero waste & & Fabric. \\
\hline & pattern development. & & \\
\hline \multirow[t]{3}{*}{ Maxi Dress } & I00\% organic cotton elastic & Fashion School & White digitally printed denim. \\
\hline & waist and chest. & Print Skirt & \\
\hline & & $98 \%$ cotton $2 \%$ spandex stretch & \\
\hline \multirow[t]{3}{*}{ Elastic waist Skirt. } & $100 \%$ cotton printed jersey. & Blue Hooded Sweatshirt & $100 \%$ organic cotton up cycled \\
\hline & using zero waste pattern & & jersey digitally printed hood and \\
\hline & development. & & kangaroo pocket. \\
\hline
\end{tabular}

Students enrolled in an introductory fashion industry course completed a three-part questionnaire developed to collect information about clothing attributes and purchase intentions for the ten sustainably designed garments. Students were also asked to complete ${ }^{55}$ fashion leadership scale.

The first part of the survey asked about clothing attributes for each of the ten garments measured with a 10-point scale, ranging from 1 (lowest) to 10 (highest). After rating the attributes, participants separately indicated purchase intention. The option, "I have no interest in purchasing this product" was also included. The survey included questions about demographics (age, gender, ethnicity, and year in college).
The survey measured fashion leadership through nine Likert-type items with a five-point rating from strongly disagrees to strongly agree. This scale was developed by Goldsmith $\mathrm{RE}^{55}$ and included ${ }^{56}$ five fashion leadership scales. Goldsmith et al. ${ }^{53}$ reported a single factor accounting for $64 \%$ of the variance extracted with Cronbach's alpha reliability coefficient of .85 in Table 2.

The Statistical Package for the Social Sciences (v. 20) (SPSS) was used for all data analyses. All nine original items of fashion leadership resulted in one primary factor with a Cronbach's alpha score of .86 using principal component analyses with Varimax rotation. A mediansplit method was adopted to divide participants into two groups: low vs. high fashion leadership. An Independent T- Test was conducted 
with the two fashion leadership groups to compare clothing attributes for each garment. Simultaneous multiple regression was conducted to investigate the clothing attributes to predict purchase intention. Finally, an individual ANOVA was used to evaluate combined clothing attributes and purchase intention between two fashion leadership groups.

\section{Results and discussion}

\section{Results}

A. Demographics: One hundred thirty-six students completed the survey. Overall, 90\% $(n=123)$ were female and $8.8 \%(n=12)$ were male. The average age of the respondents was 19 (ranging from 18 to 26 years; $\mathrm{SD}=1.51 ; \mathrm{n}=130$ ). Approximately $64 \%$ $(\mathrm{n}=87)$ of the respondents were Caucasian, followed by African or African American $(21 \% ; n=28)$, Asian $(8 \% ; n=11)$, and Latino or Hispanic $(6 \% ; n=8) .68 \%(n=92)$ of the respondents were freshmen followed by sophomores $(24 \% ; n=32)$. Almost three fifths of the students were Fashion Merchandising majors (59\%; $\mathrm{n}=80$ ) and the rest of the students majored in Fashion Design $(21 \% ; n=28)$ or other majors $(20 \% ; n=28)$.

\section{Fashion leadership}

Responses for the nine items on the fashion leadership scale were averaged and ranged from 3.38 to 4.50 . Median score above 3.77 were designated high in fashion leadership (HL) and those below designated low in fashion leadership (LL). Of the 136 students who participated, $48 \%(n=59)$ were classified as HL and $52 \%(n=64)$ as LL.

\section{Fashion leadership and clothing attributes}

In order to test H1, we used a SPSS Independent Sample T-Test to individually test each garment regarding whether the high and low leadership groups differed in their clothing attribute ratings. Ratings were significantly different between the groups on at least one attribute for six of the products: "FS" Print Skirt, Red Jacket, Blue Hooded Jacket, Drawstring Skirt, Wrap Skirt, and Sweatshirt.

The HL group did not provide higher ratings than the LL on all garments nor did they provide higher ratings on all eight attributes. Yet, for six of the ten garments, the HL group provided higher ratings. A summary is shown in Table 2, followed by presentation of results for individual products.

"FS" print skirt: The high leadership (HL) group was significantly different from the low leadership (LL) on color $(\mathrm{t}=2.29, \mathrm{p}=.024$, HL mean $=7.95, \mathrm{LL}=7.22)$, durability $(\mathrm{t}=3.33, \mathrm{p}=.001$, HL mean $=7.48, \mathrm{LL}$ mean=6.53), fabric $(\mathrm{t}=2.22, \mathrm{p}=.028$, HL mean=7.76, LL mean=7.03), general appearance $(\mathrm{t}=2.35, \mathrm{p}=.02, \mathrm{HL}$ mean $=8.60, \mathrm{LL}$ mean $=7.86)$, and style/fashion $(\mathrm{t}=2.62, \mathrm{p}=.01$, HL mean $=8.75$, LL mean $=7.83)$.

Red jacket: The high leadership (HL) group was significantly different from the low leadership (LL) on general appearance $(t=2.31$, $\mathrm{p}=.023$, HL mean $=8.45$, LL mean $=7.57)$ and style/fashion $(\mathrm{t}=2.87$, $\mathrm{p}=.005$, HL mean $=8.77$, LL mean $=7.68$ ).

Blue hooded jacket: The high leadership (HL) group was significantly different from the low leadership (LL) on durability $(\mathrm{t}=2.39, \mathrm{p}=.018$, HL mean $=8.86$, LL mean $=8.19)$ and style/fashion $(\mathrm{t}=2.05, \mathrm{p}=.043$, HL mean $=8.91$, LL mean $=8.25$ ).

Drawstring skirt: The high leadership (HL) group was significantly different from the low leadership (LL) on comfort $(\mathrm{t}=2.13, \mathrm{p}=.035$, HL mean $=8.41$, LL mean=7.76), durability $(t=2.29, p=.024$, HL mean $=8.18$, LL mean $=7.51)$, and general appearance $(t=2.11, \mathrm{p}=.037$, HL mean=8.66, LL mean=7.97).

Table 2 Fashion Leadership Items

I It important to me that my clothes be of the latest style.

2 I usually have one or more outfits that are of the very latest style.

3

When I choose between the two, I usually dress for fashion, not for comfort.

4 I closely monitor fashionable trends.

5 lam aware of fashion trends and want to be one of the first to try them.

lam the first to try new fashion; therefore; many people regard me as being a fashion leader.

7 It is important for me to be a fashion leader.

8

Clothes are one of the most important ways I have of expressing my individuality.

9 lam confident in my ability to recognize fashion trends.

Wrap skirt: The high leadership (HL) group was significantly different from the low leadership (LL) only on comfort ( $\mathrm{t}=2.07$, $\mathrm{p}=0.041$, HL mean $=9.05$, LL mean $=8.59$ ).

Sweatshirt: The high leadership (HL) group was significantly different from the low leadership (LL) on comfort $(\mathrm{t}=3.33, \mathrm{p}=.001$, HL mean=9.47, LL mean=8.76), durability $(\mathrm{t}=2.64, \mathrm{p}=.009$, HL mean $=8.73$, LL mean $=7.97)$, ease of care $(t=2.48, p=.014$, HL mean $=8.78$, LL mean=8.10), and fabric $(t=2.26, p=.026$, HL mean $=8.53$, LL mean $=7.85$ ).

\section{Clothing attributes and purchase intention}

To test $\mathrm{H} 2$, simultaneous multiple regression was conducted to investigate the clothing attributes as a prediction of purchase intention for the ten garments. The summary of variables that significantly related to purchase intention of each garment can be found in Table 3 . As a result, all variables including color, comfort, durability, ease of care, fabric, fit, general appearance and style/fashion were significantly related to purchase intention for eight out of ten garments. Ease of care had an insignificant relationship with purchase intention for two out of ten garments. Also, fabric had an insignificant relationship with purchase intention for only one garment. However, the combination of all variables to predict purchase intention was statistically significant for each garment. Results for each garment will be presented after the summary table.

"FS" print skirt: The combination of all variables to predict purchase intention was statistically significant, $F(8,103)=6.27, p<.001$. Only style/fashion significantly added to the prediction when the other seven variables were already considered. The adjusted $\mathrm{R}^{2}$ value was .275 indicating that $27.5 \%$ of the variance in purchase intention was explained by the model.

White crop top: The combination of all variables to predict purchase intention was statistically significant, $\mathrm{F}(8,110)=12.47$, $\mathrm{p}<.001$. Only general appearance significantly added to the prediction when the 
other seven variables were already considered. The adjusted $\mathrm{R}^{2}$ value was .437 indicating that $43.7 \%$ of the variance in purchase intention was explained by the model.

Red jacket: The combination of all variables to predict purchase intention was statistically significant, F $(8,109)=19.006, \mathrm{p}<.001$. Only Fit and Style/Fashion significantly added to the prediction when the other six variables were already considered. The adjusted $\mathrm{R}^{2}$ value was .552 indicating that $55.2 \%$ of the variance in purchase intention was explained by the model.

Table 3 Summary of Clothing Attributes Between High and Low Fashion Leadership Groups

\begin{tabular}{|c|c|c|c|c|c|c|}
\hline Variable & FS print skirt & Red jacket & Blue hooded jacket & Drawstring skirt & Wrap skirt & Sweatshirt \\
\hline Color & $x$ & & & & & \\
\hline Comfort & & & & $x$ & $x$ & $x$ \\
\hline Durability & $x$ & & $x$ & $x$ & & $x$ \\
\hline Ease of Care & & & & & & $x$ \\
\hline Fabric & $x$ & & & & & $x$ \\
\hline \multicolumn{7}{|l|}{ Fit } \\
\hline $\begin{array}{l}\text { General } \\
\text { appearance }\end{array}$ & $x$ & $x$ & & $x$ & & \\
\hline Style/Fashion & $x$ & $x$ & $x$ & & & \\
\hline
\end{tabular}

Vest: The combination of all variables to predict purchase intention was statistically significant, $F(8,107)=17.709, \mathrm{p}<.001$. Only comfort, ease of care, and general appearance significantly added to the prediction when the other five variables were already considered. The adjusted $\mathrm{R}^{2}$ value was .538 indicating that $53.8 \%$ of the variance in purchase intention was explained by the model.

Maxi dress: The combination of all variables to predict purchase intention was statistically significant, $F(8,110)=18.065, \mathrm{p}<.001$. Only color and fit significantly added to the prediction when the other six variables were already considered. The adjusted $\mathrm{R}^{2}$ value was .536 indicating $53.6 \%$ of the variance in purchase intention was explained by the model.

Laser cut top: The combination of all variables to predict purchase intention was statistically significant, $\mathrm{F}(8,108)=11.091, \mathrm{p}<.001$. Only general appearance significantly added to the prediction when the other six variables were already considered. The adjusted $\mathrm{R}^{2}$ value was .410 indicating $41.0 \%$ of the variance in purchase intention was explained by the model.

Blue hooded jacket: The combination of all variables to predict purchase intention was statistically significant, F (8, $109=12.928, \mathrm{p}<.001$. Only style/fashion significantly added to the prediction when the other six variables were already considered. The adjusted $\mathrm{R}^{2}$ value was .449 indicating that $44.9 \%$ of the variance in purchase intention was explained by the model.

Drawstring skirt: The combination of all variables to predict purchase intention was statistically significant, $F(8,107)=9.207$, $p<.001$. Only general appearance significantly added to the prediction when the other six variables were already considered. The adjusted $\mathrm{R}^{2}$ value was .363 indicating that $36.3 \%$ of the variance in purchase intention was explained by the model.

Wrap skirt: The combination of all variables to predict purchase intention was statistically significant, $\mathrm{F}(8,109)=10.454, \mathrm{p}<.001$. Only general appearance significantly added to the prediction when the other six variables were already considered. The adjusted $\mathrm{R}^{2}$ value was .393 indicating that $39.3 \%$ of the variance in purchase intention was explained by the model.

Sweatshirt: The combination of all variables to predict purchase intention was statistically significant, $\mathrm{F}(8,109)=13.014, \mathrm{p}<.001$. Only fit and general appearances significantly added to the prediction when the other five variables were already considered. The adjusted $\mathrm{R}^{2}$ value was .451 indicating $45.1 \%$ of the variance in purchase intention was explained by the model.

\section{Fashion leadership, clothing attributes, and purchase intention}

In $\mathrm{H} 3$ testing, all ten clothing attribute scores were combined then divided by ten to calculate the average clothing attribute score for each garment. The ANOVA results of the combined mean clothing attribute scores and purchase intention compared between the high and low fashion leadership groups can be found in Table 4. The results of ANOVA test showed that the high leadership group scored significantly higher on two out of ten garments: "FS" Print Skirt $[F(15,210)=7.914, p<.01]$ and Sweatshirt $[F(10,268) 4.489, p<.05]$.

Table 4 Summary of Variables That Significantly Related to Purchase Intention of Each Garment

\begin{tabular}{|c|c|c|c|c|c|c|c|c|c|c|}
\hline Variable & I & 2 & 3 & 4 & 5 & 6 & 7 & 8 & 9 & 10 \\
\hline Color & $x$ & $x$ & $x$ & $x$ & $x$ & $x$ & $x$ & $x$ & $x$ & $x$ \\
\hline Comfort & $x$ & $x$ & $x$ & $x$ & $x$ & $x$ & $x$ & $x$ & $x$ & $x$ \\
\hline Durability & $x$ & $x$ & $x$ & $x$ & $x$ & $x$ & $x$ & $x$ & $x$ & $x$ \\
\hline Ease of Care & & $x$ & $x$ & $x$ & $x$ & $x$ & $x$ & & $x$ & $x$ \\
\hline Fabric & $x$ & $x$ & $x$ & $x$ & $x$ & $x$ & $x$ & & $x$ & $x$ \\
\hline Fit & $x$ & $x$ & $x$ & $x$ & $x$ & $x$ & $x$ & $x$ & $x$ & $x$ \\
\hline $\begin{array}{l}\text { General } \\
\text { Appearance }\end{array}$ & $x$ & $x$ & $x$ & $x$ & X & $x$ & $x$ & $x$ & $x$ & $x$ \\
\hline Style/Fashion & $x$ & $x$ & $x$ & $x$ & $x$ & $x$ & $x$ & $x$ & $x$ & $x$ \\
\hline
\end{tabular}

Note I, "FS" Print skirt, 2,White Crop Top, 3, Red Jacket, 4,Vest, 5, Maxi Dress, 6, Laser Cut Top, 7, Blue Hooded Jacket, 8, Drawstring skirt, 9, Wrap Skirt, 10, Sweatshirt.

However, results did not show that the high fashion leadership group rated significantly higher on purchase intention than the low fashion leadership group as shown in Table 5. 
Table 5 ANOVA Results of Combined Mean Scores of Clothing Attributes, Purchase Intention With Fashion Leadership Groups

\begin{tabular}{|c|c|c|c|c|c|}
\hline Garment & Fashion leadership & $\mathbf{N}$ & $\begin{array}{l}\text { Clothing } \\
\text { attribute mean }\end{array}$ & $\mathbf{F}$ & Sig. \\
\hline \multirow[t]{2}{*}{ I } & $\mathrm{LL}$ & 56 & 7.01 & 7.914 & $0.006 * *$ \\
\hline & $\mathrm{HL}$ & 58 & 7.73 & & \\
\hline \multirow[t]{2}{*}{2} & LL & 58 & 7.35 & 0.063 & 0.8 \\
\hline & $\mathrm{HL}$ & 64 & 7.28 & & \\
\hline \multirow[t]{2}{*}{3} & LL & 57 & 7.43 & 3.745 & 0.06 \\
\hline & $\mathrm{HL}$ & 64 & 8 & & \\
\hline \multirow[t]{2}{*}{4} & $\mathrm{LL}$ & 58 & 7.05 & 1.709 & 0.19 \\
\hline & $\mathrm{HL}$ & 62 & 7.55 & & \\
\hline \multirow[t]{2}{*}{5} & LL & 58 & 8.32 & 0.036 & 0.85 \\
\hline & $\mathrm{HL}$ & 64 & 8.37 & & \\
\hline \multirow[t]{2}{*}{6} & LL & 58 & 8.29 & 0.009 & 0.93 \\
\hline & $\mathrm{HL}$ & 64 & 8.31 & & \\
\hline \multirow[t]{2}{*}{7} & LL & 59 & 8.29 & 1.975 & 0.16 \\
\hline & $\mathrm{HL}$ & 63 & 8.64 & & \\
\hline \multirow[t]{2}{*}{8} & $\mathrm{LL}$ & 57 & 8.02 & 1.904 & 0.17 \\
\hline & $\mathrm{HL}$ & 63 & 8.52 & & \\
\hline \multirow[t]{2}{*}{9} & LL & 59 & 8.51 & 1.991 & 0.16 \\
\hline & $\mathrm{HL}$ & 64 & 8.83 & & \\
\hline \multirow[t]{2}{*}{10} & LL & 59 & 7.83 & 4.489 & $0.04 *$ \\
\hline & $\mathrm{HL}$ & 64 & 8.4 & & \\
\hline \multirow[t]{2}{*}{$\begin{array}{l}\text { Purchase } \\
\text { Intention }\end{array}$} & LL & 52 & 4.93 & 0.305 & 0.58 \\
\hline & $\mathrm{HL}$ & 57 & 5.04 & & \\
\hline
\end{tabular}

Note I, “FS” Print Skirt, 2, White Crop Top, 3, Red Jacket, 4,Vest, 5, Maxi Dress, 6, Laser Cut Top, 7, Blue Hooded Jacket, 8, Drawstring Skirt, 9, Wrap Skirt, I0, Sweatshirt. HL, high leadership. LL, Low leadership. *p., <.05."it<.01

\section{Discussion}

The purpose of this study was to examine the effect of fashion leadership and clothing attributes on purchase intention of ten sustainable products developed for a school-sponsored store. This was done by testing three hypotheses. When Hypothesis one was tested, results showed that high and low fashion leadership group ratings were significantly different on six of the ten products, with the high group scoring higher than the low group on at least one attribute. Among those, the high group scored higher on durability (four garments out of six), followed by general appearance (four garments), style/fashion (three garments), and comfort (three garments). This result indicates that if there is a difference between the high and low leadership groups on clothing attributes, the high leadership group will likely have a higher rating. This result confirmed previous studies that high fashion leadership consumers tend to evaluate clothing attributes more positively than those with low fashion leadership Beaudoin et al. ${ }^{42}$; Kincade et al. ${ }^{9 \cdot 10}$ Therefore, it is suggested from this study that if companies would like to attract more high leadership customers for sustainable products, they should focus on durability, general appearance, style/fashion, and comfort clothing attributes.

As we hypothesized, for most of the ten garments, general appearance and style/fashion were the most significant influencers of purchase intention. The majority of the variables were important predictors; however, ease of care and fabric were insignificant influencers on two of the garments. The results of this study confirmed previous studies that different criteria influenced consumers' purchase intentions and their overall acceptance of fashion products; ${ }^{12,13}$ Eckman et al. ${ }^{39},{ }^{14,16}$ Herrata-Corredor et al. ${ }^{15}$ This result is consistent with previous research that fashion/style and appearance were the most important attributes to young consumers and women when making a purchase decision; ${ }^{43}$ North et al ${ }^{46}$ For the future, apparel companies should pay more attention to the style/fashion attribute to promote sustainable products to these target customers.

Hypothesis three was partially supported in our study. The high fashion leadership group scored significantly higher on sustainable clothing attributes than the low fashion leadership group on two out of ten garments: "FS" Print Skirt and Sweatshirt. These can be considered the most specialized garments, featuring a digitally printed Fashion School store logo and a student designed up cycled style. Although the high fashion leadership group only provided higher ratings on two of ten clothing attributes for these garments, this study can be a starting point for investigating relationships between fashion leadership and sustainable clothing attributes. Higher ratings on 
attributes by fashion leaders can provide insights into those products that may have a greater chance of consumer acceptance. Consumers high in fashion leadership are the first to buy and wear new fashions; they persuade others to buy and wear new fashions. ${ }^{41}$ The results of this study can be used to identify sustainable clothing attributes that will appeal to fashion leaders to promote sustainable products to a broader consumer base as suggested by D Souza et al. ${ }^{6}$

Contrary to hypothesis three, our results showed that there was not a significant difference between high and low fashion leadership groups towards purchase intention for each of the individual products. Both the high and low leadership groups provided high overall purchase intention ratings for most of the ten garments. This is somewhat different from ${ }^{5}$ who found that fashion leaders may not show intention to purchase sustainable clothing products. This finding may lend support to D Souza et al. ${ }^{6}$ who concluded that "green is not yet the new black", at least for college students.

\section{Conclusion}

As awareness of the negative environmental impact of the fashion industry increases, this study demonstrated sustainable products can be attractive to young consumers regardless of their fashion leadership level. Positive purchase intention for products made with organic fabrics, zero-waste design, and local production hold promise for the future. By exploring clothing attributes and fashion leadership with ten sustainable products developed for a school-sponsored store, this research provides insights for fashion industry professionals to successfully produce and promote sustainable products, lessening the impact on the environment and improving the lives of individuals, families, and communities.

We relied on a sample of college students studying fashion design and merchandising. This sample was limited and obviously does not reflect all target customers who shop at the school-sponsored store. However, with the location of the school-sponsored store close to campus and easily accessible to college students, this approach seemed to be a reasonable way to select a sample for the study. Future studies can be done to identify a broader target customer range for the school-sponsored store since the products created for the store are of premium quality featuring unique design. For example, data can be collected from older consumers who would most likely to be interested in quality and uniqueness than college students. Other types of clothing can be also tested to measure the relationship between clothing attributes and fashion leadership. Individual demographics such as income level, social status, and age can be further investigated in relation to purchase intention as well as varying the clothing attributes can provide additional practical implications for the schoolsponsored store.

\section{Acknowledgments}

None.

\section{Conflict of interest}

Author declares there is no conflict of interest in publishing the article.

\section{References}

1. US Bureau of Labor Statistics. Fashion. USA; 2012.

2. Fashion United. Global fashion industry statistics-International apparel. USA; 2014.
3. D Souza C, Taghian M, Lamb P, et al. Green products and corporate strategy: an empirical investigation. Society and Business Review. 2006;1(2):144-157.

4. Shen B, Wang Y, Lo CK, et al. The impact of ethical fashion on consumer purchase behavior. J Fashion Marketing \& Management: An International J. 2012;16(2):234-245.

5. Gam HJ. Are fashion-conscious consumers more likely to adopt eco-friendly clothing?. J Fashion Marketing \& Management: An International J. 2011;15(2):178-193.

6. D Souza C, Gilmore AJ, Hartmann P, et al. Male eco-fashion: a market reality. International J Consumer Studies. 2015;39(1):35-42.

7. Goldsmith RE, Heitmeyer JR, Freiden JB. Social values and fashion leadership. Clothing \& Textiles Res J. 1991;10(1):37-45.

8. Kaiser SB. The social psychology of clothing: Symbolic appearances in context. 2nd edn. Fairchild Books, New York, USA; 1997.

9. Kincade DH, Kim J, Gibson F. Generational consumer segments and shopping process characteristics: Baby boomers and echo boomers with apparel product selection activities. J Global Fashion Marketing. 2010;1(1):19-29.

10. O Cass A. An assessment of consumers product, purchase decision, advertising and consumption involvement in fashion clothing. $J$ Economic Psychology. 2000;21(5):545-576.

11. Hines JD, O Neal GS. Underlying determinants of clothing quality: the consumers' perspective. Clothing \& Textiles Res J. 1995;13(4):227-233.

12. Baugh DF, Davis LL. The effect of store image on consumers' perceptions of designer and private label clothing. Clothing \& Textiles Res J. 1989;7(3):15-21.

13. Behling DU, Wilch J. Perceptions of branded clothing by male consumers. Clothing \& Textiles Res J. 1988;6(2):43-47.

14. Heisey FL. Perceived quality and predicted price: Use of the minimum information environment in evaluating apparel. Clothing \& Textiles Res J. 1990;8(4):22-28.

15. Herrera Corredor JA, Saidu JE, Khachatryan A, et al. Identifying drivers for consumer acceptance and purchase intent of corn tortilla. Journal of food scienc J Food Sci. 2007;72(9):S727-S731.

16. Rajagopal D. Measuring Asymmetric Consumer Behavior towards Retail Buying: Application of Demand Equation Models. Monterrey Instititue of Technology, Marketing and Business Working Paper. 2006.

17. Beaudoin P, Moore MA, Goldsmith RE. Fashion leaders' and followers' attitudes toward buying domestic and imported apparel. Clothing \& Textiles Res J. 2000;18(1):56-64.

18. Cho Che J, Kang J. Underlying dimensions of fashion opinion leadership. Proceedings International Textile \& Apparel Association. 1996.

19. Flynn LR, Goldsmith RE, Kim WM. A cross-cultural validation of three new marketing scales for fashion research: Involvement, opinion seeking and knowledge. J Fashion Marketing \& Management: An International J. 2000;4(2):110-120.

20. Kang J, Park Poaps H. Hedonic and utilitarian shopping motivations of fashion leadership. $J$ of Fashion Marketing \& Management: An International J. 2010;14(2):312-328.

21. Phau I, Lo CC. Profiling fashion innovators: A study of self-concept, impulse buying and Internet purchase intent. J Fashion Marketing \& Management: An International J. 2004;8(4):399-411.

22. Jackson J. Assessing the environmental impact of the fashion world. 2014. 
23. Lo CKY, Yeung ACL, Cheng TCE. The impact of environmenta management systems on financial performance in fashion and textiles industries. International J Production Economics. 2012;135(2):561-567.

24. Borghesi S, Vercelli A. Sustainable globalization. Ecological Economics 2003;44(1):77-89.

25. Caniato F, Caridi M, Crippa L, et al. Environmental sustainability in fashion supply chains: An exploratory case based research. International $J$ production economics. 2012;135(2):659-670.

26. Bland B. A new, sustainable model for apparel manufacturing in the US 2013.

27. Phelan H. 10 Eco-friendly fashion brands we can get behind. 2012.

28. Clark A. Fashion forward: Innovations drive sustainable clothing. Green Biz Group Inc, USA; 2013.

29. Ethical Fashion Forum. Organic \& eco fashion. 2015.

30. Lolli A. Stella McCartney: Fashion and sustainability. FG Magazine. 2015

31. Patagonia and Organic Cotton: A Case Study. Patagonia, USA; 2015.

32. Rissanen T. From $15 \%$ to 0 : Investigating the creation of fashion without the creation of fabric waste. Academia. 2013.

33. Liu M. What is Zero-Waste Fashion (and Why Does it Matter). Ecouterre. 2010

34. Rodie J. From Waste To Worth. 2010.

35. Rosenbloom S. Fashion tries on zero waste design. Fashion \& Style 2010

36. Gonzalez AI. Is America Ready for "Made in the U.S.A." Clothing Manufacturing Industry Advisor. 2014.

37. Organic Trade Association. Organic Cotton Facts. USA; 2012.

38. The Nielsen Company. Global consumers are willing to put their money where their hear is when it comes to goods and services from companies committed to social responsibility. 2014.

39. Eckman M, Damhorst ML, Kadolph SJ. Toward a model of the in-store purchase decision process: Consumer use of criteria for evaluating women's apparel. Clothing \& Textiles Res J. 1990;8(2):13-22.

40. Bucklye E. Product development from a student's perspective. Snack Food \& Wholesale Bakery. 2013

41. Cho S, Workman J. Gender, fashion innovativeness and opinion leadership, and need for touch: Effects on multi-channel choice and touch/non-touch preference in clothing shopping. J Fashion Marketing \& Management: An International J. 2011;15(3):363-382.
42. Beaudoin P, Moore MA, Goldsmith RE. Young fashion leaders' and followers' attitudes toward American and imported apparel. J Product \& Brand Management. 1998;7(3):193-207.

43. Kaushal SK. The Importance of Apparel Product Attributes for Teenaged Buyers. NMIMS Management Review. 2013;23:45-64.

44. Kim HS, Damhorst ML, Lee KH. Apparel involvement and advertisement processing: A model. J Fashion Marketing \& Management: An International J. 2002;6(3):277-302.

45. Birtwistle G, Freathy P. More than just a name above the shop: comparison of the branding strategies of two UK fashion retailers. International J Retail \& Distribution Management. 1998;26(8):318-323.

46. North EJ, De Vos RB, Kotze T. The importance of apparel product attributes for female buyers. J Family Ecology \& Consumer Sciences Tydskrif vir Gesinsekologie en Verbruikerswetenskappe. 2003:31.

47. Evans M. Consumer behavior towards fashion. European J of Marketing 1989;23(7):7-16.

48. Goldsmith RE, Flynn LR, Moore MA. The self-concept of fashion leaders. Clothing \& Textiles Res J. 1996;14(4):242-248.

49. Morganosky MA, Vreeman AL. The involvement concept: Relations to the apparel consumer. University of Illinois at Urbana. 1986.

50. Wilkie WL. Consumer behavior. 3rd edn. John Wiley \& Sons, New York, USA; 1994.

51. Painter JJ, Pinegar ML. Post-high teens and fashion innovation. $J$ Marketing Research. 1971;8(3):368-369.

52. Rogers EM. Diffusion of Innovations. $3^{\text {rd }}$ edn. The Free Press, New York, USA; 1983.

53. Goldsmith R, Stith M. The social values of fashion innovators. J Applied Business Research. 1993;9(1):10-17.

54. Kang J, Park Poaps H. Motivational antecedents of social shopping for fashion and its contribution to shopping satisfaction. Clothing \& Textiles Res J. 2011;29(4):331-347.

55. Goldsmith RE, Frieden JB, Kilsheimer JC. Social values and female fashion leadership: A cross-cultrual study, Psychology \& Marketing. 1993;10(5):399-412.

56. Gutman J, Mills MK. Fashion life-style, self-concept, shopping orientation, and store patronage-an integrative analysis. $J$ Retailing. 1982;58(2):64-86 